\title{
Hydrogenosomes of Metopus contortus physiologically resemble mitochondria
}

\author{
Giancarlo A. Biagini, ${ }^{1}$ Anthony J. Hayes, ${ }^{2}$ Marc T. E. Suller, ${ }^{1}$ \\ Carole Winters, ${ }^{1}$ Bland J. Finlay ${ }^{3}$ and David Lloyd'
}

Author for correspondence: Giancarlo A. Biagini. Tel: +44 1222 874772. Fax: +44 1222874305. e-mail: sab3gab@cardiff.ac.uk

\footnotetext{
1,2 Microbiology Group, $\mathrm{PABIO}^{1}$, and Anatomy Unit, MOMED2, University of Wales College of Cardiff, PO Box 915 Cardiff CF1 3TL, UK

3 Institute of Freshwater Ecology, Windermere Laboratory, The Ferry House, Ambleside, Cumbria LA22 OLP, UK
}

\begin{abstract}
The anaerobic free-living ciliated protozoon Metopus contortus is a grazer in anoxic marine sediments. It does not possess mitochondria, but it does have specialized organelles termed hydrogenosomes which release hydrogen gas. The cationic lipophilic cyanine dye $\operatorname{DiOC}_{7}(3)$ is an indicator of transmembrane electrochemical potential. With the aid of confocal laser scanning microscopy (CLSM), the association of this dye with hydrogenosomes in situ was followed. Flow cytometric measurements showed that fluorescence of the membrane potential dye decreased in response to an elevated $\mathrm{pH}_{2}$ in the cell. CLSM also revealed localization of fluorescence of the calcium probe Fluo 3-AM, and of the transmembrane pH gradient probe BCECF-AM, within the lumen of the hydrogenosomes. In addition, hydrogenosomal inclusions were detected. X-ray microanalysis of these electron-dense granules revealed high levels of calcium, phosphate and magnesium. It is concluded that $M$. contortus hydrogenosomes are calcium stores, have a membrane potential, and an alkaline lumen. These physiological features resemble those of mitochondria in aerobic protozoa.
\end{abstract}

Keywords: Metopus contortus, hydrogenosomes, transmembrane electrochemical potential, transmembrane $\mathrm{pH}$ gradient, calcium phosphate inclusions

\section{INTRODUCTION}

Metopus contortus, a free-living ciliate, is a ubiquitous filter-feeder in anoxic marine sediments which plays a vital role in the phagotrophic chains of anaerobic communities (Fenchel \& Finlay, 1990). It does not have mitochondria, but it does have specialized redox organelles, the hydrogenosomes, which release hydrogen gas (Finlay \& Fenchel, 1989; Fenchel \& Finlay, 1992). Hydrogenosomes are found in a phylogenetically broad range of organisms. In the parasitic flagellate Trichomonas vaginalis, the hydrogenosomes contain phosphate-bound and free calcium (Chapman et al., 1985; Humphreys et al., 1994) and have a transmembrane electrochemical potential $(\Delta \psi)$ (Humphreys et al., 1994), whilst hydrogenosomes from the rumen chytrid fungus Neocallimastix have a transmembrane $\mathrm{pH}$ gradient

Abbreviations: BCECF-AM, 2', 7'-bis(2-carboxyethyl)-5-carboxyfluorescein, acetomethyl ester; BES, bromoethanesulphonate; CLSM, confocal laser scanning microscopy; $\mathrm{DiOC}_{7}(3)$, dihexyloxacarbocyanine; Fluo 3-AM, 1-[2-amino-5-(2,7-dichloro-6-hydroxy-3-oxy-9-xanthenyl)-phenoxy]-2-(2amino-5-methylphenoxy)ethane- $N, N, N^{\prime}, N^{\prime}$-tetraacetic acid, acetomethyl ester.
$(\Delta \mathrm{pH})$ and a novel ATPase (Marvin-Sikkema et al., 1994). The cattle parasite Tritrichomonas foetus has also been shown to possess calcium inclusions localized in the hydrogenosome (Benchimol et al., 1982). Little is known of the function of $M$. contortus hydrogenosomes within the cell or of their role in relation to the endosymbiotic methanogenic bacteria which they harbour (Finlay \& Fenchel, 1991; Embley et al., 1992). The endosymbiotic methanogenic bacteria may convert the hydrogenosomally produced hydrogen, carbon dioxide and acetate into methane and water (Fenchel \& Finlay, 1992, 1994). The apparent close juxtaposition of symbionts and hydrogenosomes (Finlay \& Fenchel, 1991) is believed to aid the hydrogen transfer (Fenchel \& Finlay, 1991, 1992). Removal of the endosymbiont, by the methanogen inhibitor bromoethanesulphonate (BES), leads to an approximately $30 \%$ reduction in growth rate and yield of the ciliate (Fenchel \& Finlay, 1991). With the aid of confocal laser scanning microscopy (CLSM) and energy-dispersive X-ray microanalysis, this study has investigated $M$. contortus hydrogenosomes for the presence of calcium, a $\Delta \psi$ and a $\Delta \mathrm{pH}$. In addition, flow cytometric measurements revealed the effect of dissolved hydrogen on the membrane potential of the hydrogenosomes. 


\section{METHODS}

Isolation and culture conditions. $M$. contortus was isolated by T. Fenchel (University of Copenhagen, Denmark) and B. J. Finlay from anaerobic marine sands in Denmark and cultured anaerobically in medium C75S in sealed glass serum vials with a nitrogen headspace at $20^{\circ} \mathrm{C}$ (Finlay \& Fenchel, 1989). Methanogen-free (asymbiotic) cells were obtained by the addition of $50 \mathrm{mM}$ BES, a selective inhibitor of methanogenic bacteria (Smith, 1983; Fenchel \& Finlay, 1991).

Electron microscopy. Cells were fixed in $2 \%(\mathrm{v} / \mathrm{v})$ paraformaldehyde and $2 \%(\mathrm{v} / \mathrm{v})$ glutaraldehyde $(1: 1$ mixture) for $10 \mathrm{~min}$, followed by transfer to $6 \%(\mathrm{v} / \mathrm{v})$ glutaraldehyde (30 min), $2 \%(\mathrm{w} / \mathrm{v}) \mathrm{OsO}_{4}$ in $0.1 \mathrm{M}$ sodium cacodylate buffer (45 min), and $0.5 \%(\mathrm{w} / \mathrm{v})$ uranyl acetate $(1 \mathrm{~h})$. Dehydration in increasing concentrations of ethanol was followed by embedding in Spurr resin and sectioning (Finlay \& Fenchel, 1989). Cells for electron probe X-ray microanalysis were single fixed in $4 \%(\mathrm{v} / \mathrm{v})$ glutaraldehyde in $0.1 \mathrm{M}$ sodium cacodylate buffer $(30 \mathrm{~min})$ followed by dehydration and embedding in LR White resin.

CLSM. Asymbiotic cells were stained with either cyanine $\mathrm{DiOC}_{7}(3)$ (final concentration $2 \mu \mathrm{g} \mathrm{ml}^{-1}$ ), BCECF-AM (final concentration $2 \mu \mathrm{g} \mathrm{ml}^{-1}$ ) or Fluo $3-\mathrm{AM}$ ( $2 \mathrm{mM}$ final concentration) for 15 min together with $2 \%(\mathrm{w} / \mathrm{v})$ DABCO $(1,4-$ diazabicyclo[2.2.2]octane), a free-radical scavenging 'antibleach' agent (Johnson et al., 1982). Methyl cellulose (10\%, $\mathrm{w} / \mathrm{v} ; \mathrm{pH} 7)$ was added to reduce the motility of the cells. A Molecular Dynamics Sarastro 2000 Confocal Scanning Microscope was used. Fluorescence excitation was set at $488 \mathrm{~nm}$ and emission at $510 \mathrm{~nm}$. Series of optical sections $(0.5 \mu \mathrm{m}$ thick) were taken through entire organisms at a spacing of $2 \mu \mathrm{m}$. Data were collected on a Silicon Graphics Indigo UNIX workstation running Molecular Dynamics 'Image Space' software.

Electron probe X-ray microanalysis. Energy-dispersive X-ray microanalysis of hydrogenosomal inclusions was carried out with a JEOL JEM-1210 transmission electron microscope equipped with a Link ATW Pentafet X-ray detector (138 eV resolution) and a Link 'ISIS' analyser (Oxford Instruments), with an accelerating voltage of $80 \mathrm{kV}$.

Flow cytometry. Asymbiotic cells were incubated with the cyanine dye $\mathrm{DiOC}_{7}(3)\left(2 \mu \mathrm{g} \mathrm{ml}^{-1}\right.$ final concentration) for $15 \mathrm{~min}$ in the presence of either hydrogen $(0.81 \mathrm{mM}$ dissolved concentration; Wilhelm et al., 1977) or nitrogen $(0.7 \mathrm{mM}$ dissolved concentration; Wilhelm et al., 1977). Flow cytometry was performed on a Skatron Argus 100 high-pressure mercury arc lamp based dual parameter flow cytometer. A fluorescein isothiocyanate filter block was used allowing excitation at $470-490 \mathrm{~nm}$, band stop at $510 \mathrm{~nm}$, and emission at $520-550 \mathrm{~nm}$. Acquisition of signals from $M$. contortus (but not from food bacteria) was determined by gating with forward angle light scatter (an indicator of cell size). Typically, fluorescence signals from 800 to 1000 asymbiotic M. contortus cells were acquired for each experiment.

\section{RESULTS}

The electron micrograph of a transverse-sectioned $M$. contortus cell confirms the peripheral localization of the hydrogenosomes and methanogens (Fig. 1a), whilst the close proximity of hydrogenosomes and methanogens is clearly demonstrated in Fig. 1(b). Treatment with the specific methanogenesis inhibitor BES appears very effective at removing the endosymbiotic methanogenic
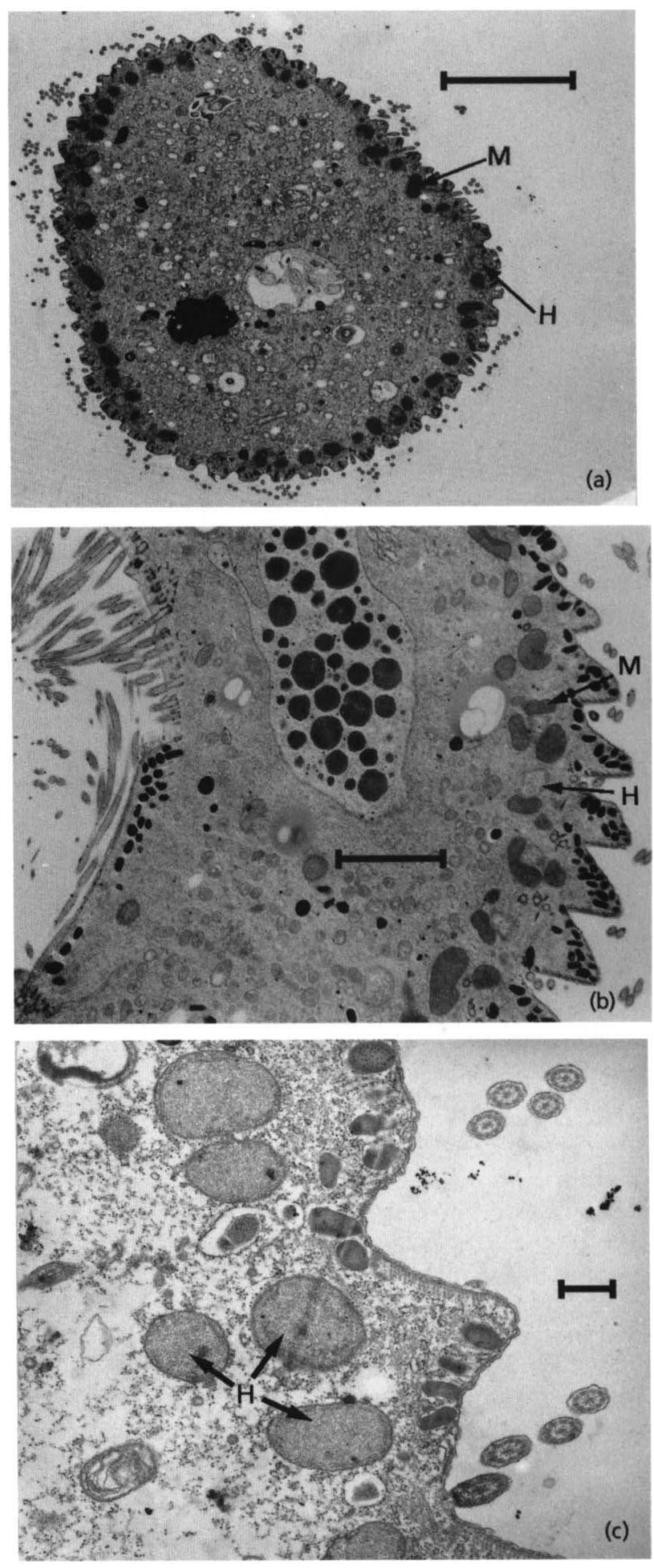

Fig. 1. Electron micrographs of $M$. contortus. (a) Transverse section of a whole cell showing the peripheral location of the hydrogenosomes $(\mathrm{H})$ and methanogens $(\mathrm{M})$; bar, $10 \mu \mathrm{m}$. (b) Methanogen/hydrogenosome complexes; bar, $2 \mu \mathrm{m}$. (c) BEStreated cells are cleared of the symbiotic methanogens, leaving only the hydrogenosomes; bar, $1 \mu \mathrm{m}$. 

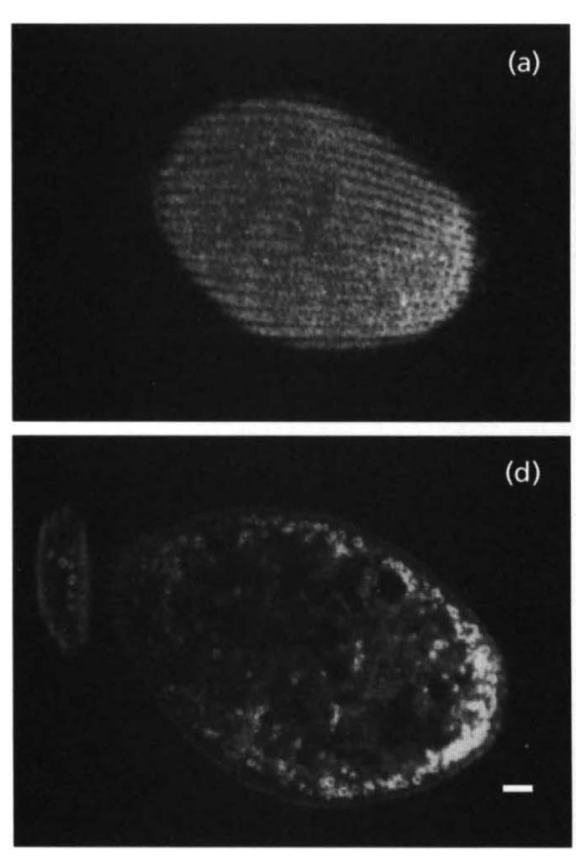
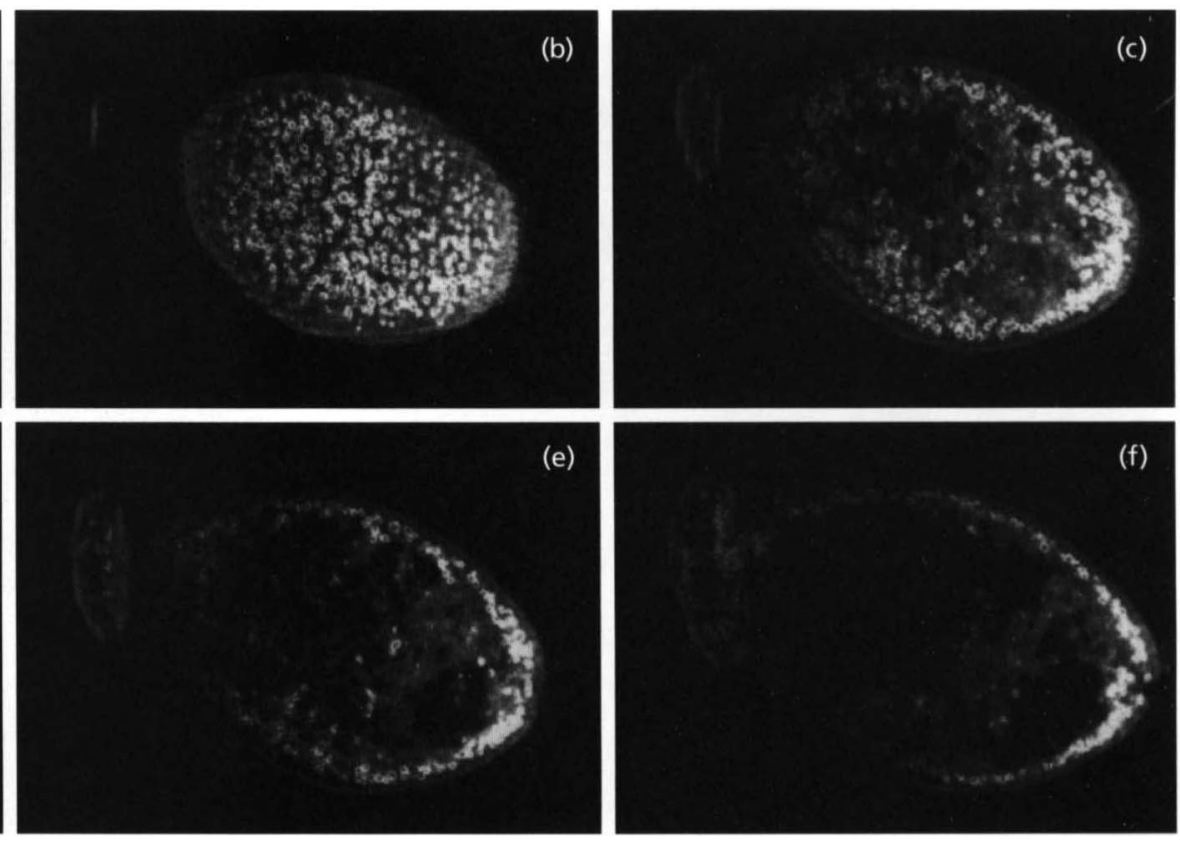

Fig. 2. (a-f) CLSM optical sections ( $0.5 \mu \mathrm{m}$ thick at $2 \mu \mathrm{m}$ increments) of a live BES-treated $M$. contortus cell stained with the cationic dye cyanine $\operatorname{DiOC}_{7}(3)\left(2 \mu \mathrm{g} \mathrm{ml}^{-1}\right)$, an indicator of $\Delta \psi$; bar, $5 \mu \mathrm{m}$.

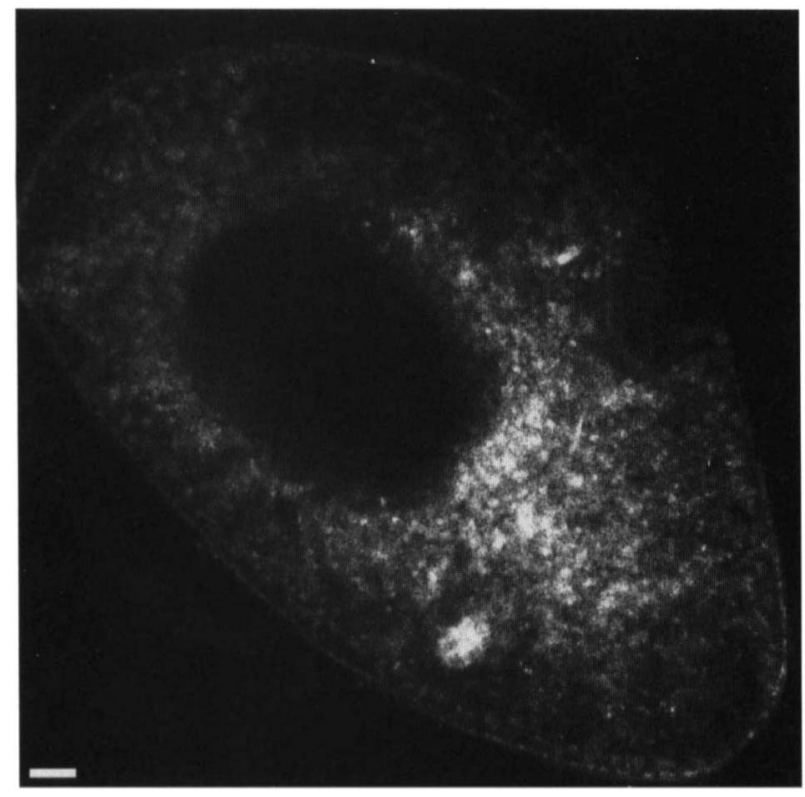

Fig. 3. CLSM single optical section of a fixed $(0.5 \%$, v/v, formalin) $M$. contortus cell incubated with cyanine $\mathrm{DiOC}_{7}(3)$ $\left(2 \mu \mathrm{g} \mathrm{ml}^{-1}\right)$. Bar, $5 \mu \mathrm{m}$.

bacteria without affecting the apparent location and morphology of the hydrogenosomes (Fig. 1c).

Specific association of the cationic lipophilic cyanine dye $\mathrm{DiOC}_{7}(3)$ to hydrogenosomes was apparent in live (Fig. 2) but not in dead (Fig. 3) protozoa, indicating the presence of a $\Delta \psi$ across the hydrogenosomal membranes. However, it was not clear to us whether the



Fig. 4. Flow cytometric measurements of live BES-treated $M$. contortus cells incubated with cyanine $\operatorname{DiOC}_{7}(3)\left(2 \mu \mathrm{g} \mathrm{ml}^{-1}\right)$ under a dissolved concentration of (a) $0.7 \mathrm{mM}$ nitrogen and (b) $0.8 \mathrm{mM}$ hydrogen.

association of the dye was to the inner or outer hydrogenosomal membrane. CLSM optical sections of the cell (Fig. 2a-f) revealed the accumulation of the dye in the cortical region where hydrogenosomes are found. No other membrane type in the cell appeared to have an affinity for the membrane potential dye.

Flow cytometric measurements of the fluorescence from the hydrogenosome-bound membrane potential dye under an atmosphere of nitrogen $(0.7 \mathrm{mM}$ dissolved concentration; Fig. 4a) was shown to decrease in response to an elevated atmosphere of hydrogen $(0.8 \mathrm{mM}$ dissolved concentration; Fig. $4 \mathrm{~b})$. A decrease in fluorescence from the membrane potential dye is directly correlated with a reduction in the $\Delta \psi$ across the hydrogenosome membranes.

Single fixed non-stained asymbiotic $M$. contortus cells were revealed to contain inclusions in the matrix (and 


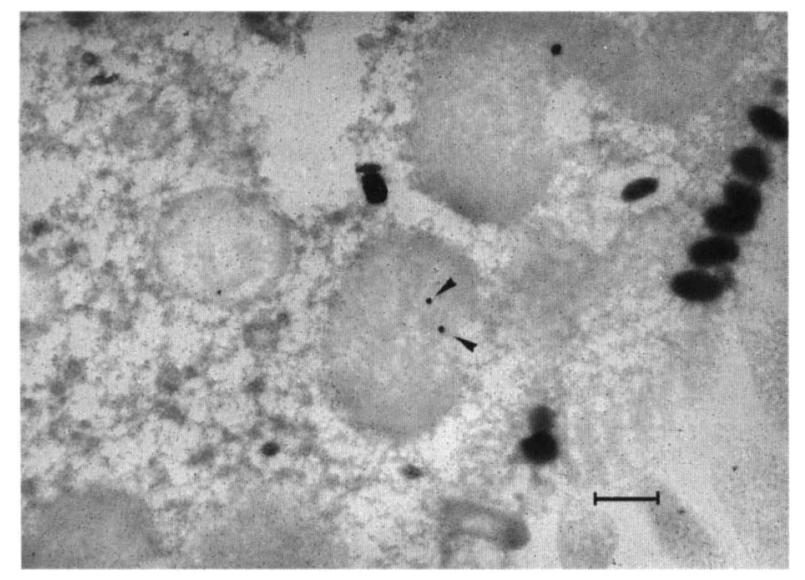

Fig. 5. Transmission electron micrograph of a single fixed nonstained asymbiotic $M$. contortus cell showing electron-dense inclusions in the hydrogenosomes (arrows). Bar, $0.5 \mu \mathrm{m}$.

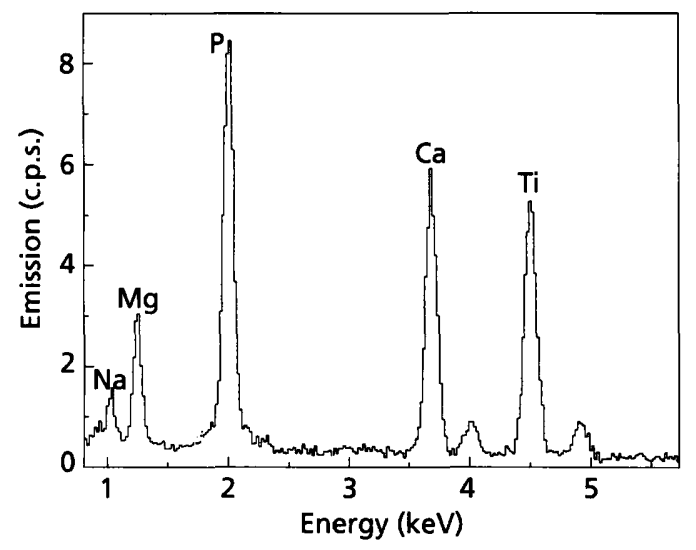

Fig. 6. Qualitative energy-dispersive $X$-ray analytical spectrum of hydrogenosomal inclusions (see Fig. 5).

sometimes in between the inner and outer membranes, not shown) of hydrogenosomes (Fig. 5). Energy-dispersive X-ray microprobe spectra of these electrondense granules revealed a high concentration of calcium and phosphate and some magnesium (Fig. 6). Background counts from the embedding resin were negligible but were nevertheless subtracted from the dot analysis of the hydrogenosomal inclusions. The titanium peak shown in the spectrum (Fig. 6) was as a result of electron scattering from the titanium grid which is used to support the samples. These results suggest that the hydrogenosomes contain calcium (and some magnesium) which has precipitated with phosphate to form the observed granules.

CLSM of live asymbiotic $M$. contortus cells loaded with the calcium-specific fluorophore Fluo 3-AM revealed the presence of calcium in the hydrogenosomes (Fig. 7). It should be noted that of the cells which were viewed, hydrogenosomal compartmentalization of the calcium

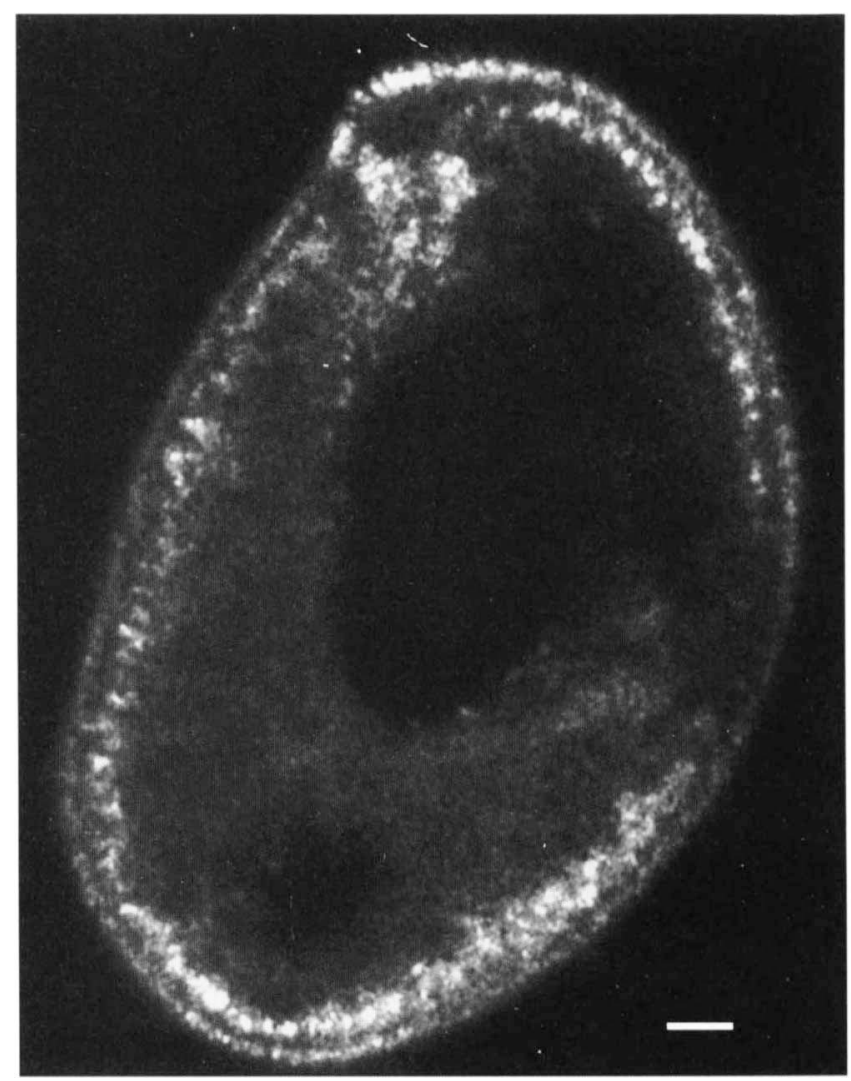

Fig. 7. CLSM optical single section of a BES-treated $M$. contortus cell stained with the calcium-specific probe Fluo 3-AM (2 $\mathrm{mM}$ ). Bar, $5 \mu \mathrm{m}$.

probe was observed only in cells which appeared damaged (i.e. cells with little ciliary movement and vacuolated cytoplasm) by the handling procedure, or those which had been over-exposed to the confocal laser. This observation suggests that higher levels of calcium may enter the hydrogenosomes during periods of cell 'stress'.

CLSM also revealed compartmentalization of the $\Delta \mathrm{pH}$ probe BCECF-AM. Optical sections of a live asymbiotic cell (Fig. 8) again revealed that the localization of the probe was in the periphery of the cells in the vicinity of the hydrogenosomes. BCECF-AM is a non-fluorescent molecule which becomes highly fluorescent within the cytoplasm where the AM group is cleaved by nonspecific esterases, yielding a highly fluorescent molecule with a pKa of 6.98. The emission intensity is $\mathrm{pH}$ dependent with greater intensity at higher $\mathrm{pH}$. The observed fluorescence indicates that the internal $\mathrm{pH}$ of hydrogenosomes is alkaline.

\section{DISCUSSION}

In this study, we have demonstrated that hydrogenosomes from the anaerobic free-living ciliate $M$. contortus possess calcium, a $\Delta \psi$ and a $\Delta \mathrm{pH}$ (inside 


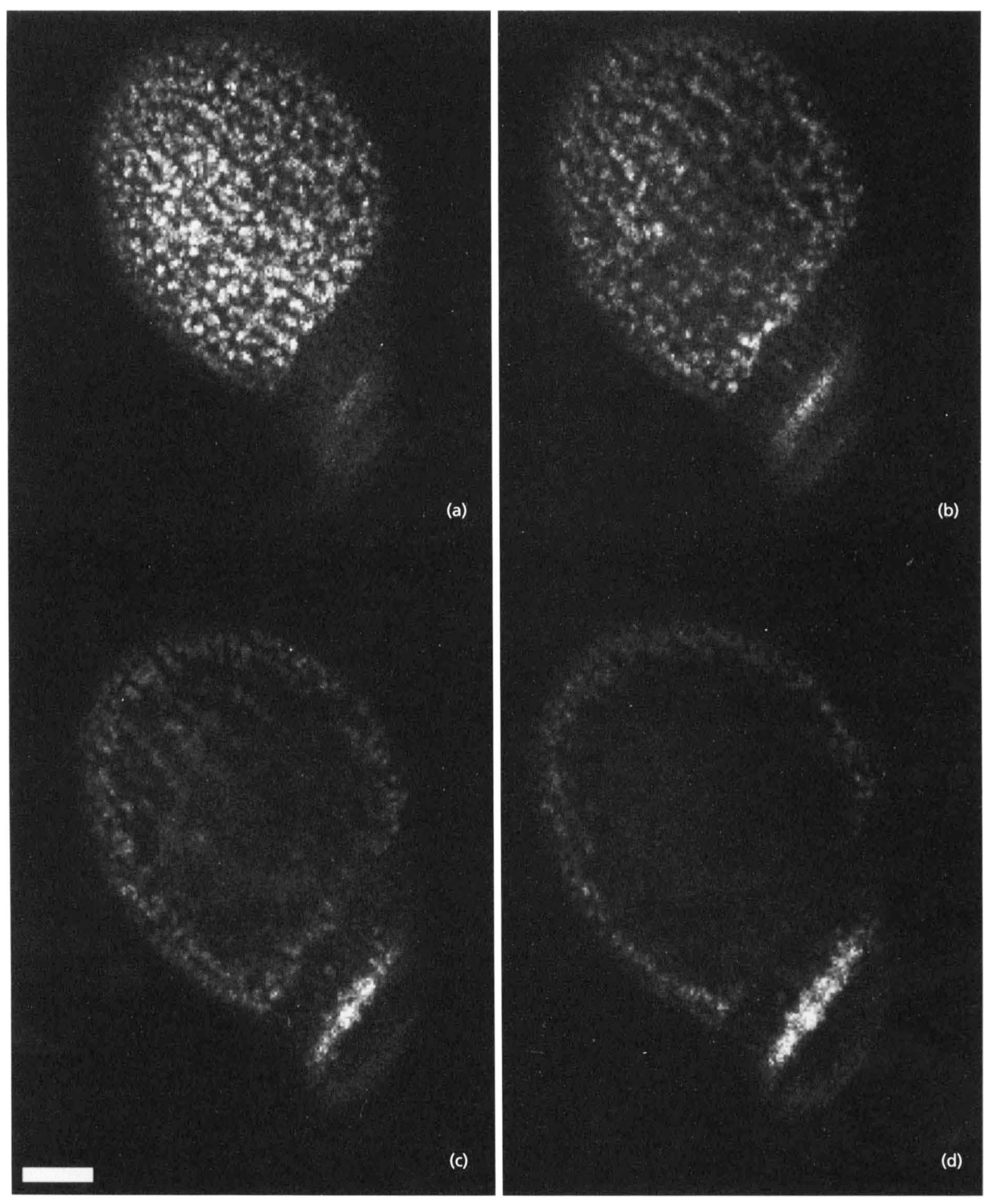

Fig. 8. (a-d) CLSM optical sections of a live BES-treated $M$. contortus cell stained with the $\triangle$ pH-specific probe BCECF-AM $\left(2 \mu \mathrm{g} \mathrm{m}^{-1}\right)$. Bar, $10 \mu \mathrm{m}$.

alkaline versus outside). Hydrogenosomes of trichomonads have been observed to have the same properties (Chapman et al., 1985; Humphreys et al., 1994; Yarlett et al., 1987); however, there is no detectable $\mathrm{F}_{0} \mathrm{~F}_{1}$-type ATPase associated with these organelles (Lloyd et al., 1979; Turner \& Luschbaugh, 1991), although it is possible that alternative energyyielding ATPases are present. Significantly, Neocallimastix hydrogenosomes contain a novel ATPase (Marvin-Sikkema et al., 1994) which is believed to 
function as a proton-translocating ATPase, which in turn generates a pH gradient across the hydrogenosomal membrane. We have yet to determine whether these organelles in $M$. contortus have ATPase activity, but it is most likely that the $\Delta \mathrm{pH}$ and $\Delta \psi$ contribute to a $\Delta p$ across the hydrogenosome membrane, enabling the import and export of metabolites and end-products. Of course, the possession of a $\Delta \psi$ is not unique to mitochondrial membranes, and it should be noted that proton gradients are present across other membrane types.

The presence of a $\Delta \mathrm{pH}$ and $\Delta \psi$ in $M$. contortus hydrogenosomes may also be exploited to drive the accumulation of calcium into hydrogenosomes, as in the case of T. foetus and T. vaginalis (Benchimol et al., 1982; Chapman et al., 1985). Mitochondria are believed to function as temporary stores of excess cytosolic calcium when the plasma membrane of a cell is injured (Carafoli, 1987). They are able to accumulate calcium at high concentrations by precipitating with phosphate, forming hydroxyapatite deposits in the matrix (Carafoli, 1987). Our results suggest that calcium uptake in the hydrogenosomes of $M$. contortus, and of other anaerobic protozoa, may be as important a mechanism as it is in mitochondria of aerobic organisms.

In recent years, the origin of hydrogenosomes has been the subject of some debate. Based on biochemical evidence, it has been suggested that hydrogenosomes originate from symbiosis with a Clostridium-like anaerobic bacterium (Müller, 1980; Whatley, 1981). The alternative explanation is that hydrogenosomes are modified mitochondria which have functionally adjusted to their anaerobic environment by way of gaining and losing specific biochemical machinery (CavalierSmith, 1987; Finlay \& Fenchel, 1989). The loss of mitochondrial characters such as cytochrome activity has been reported in the intestinal 'anaerobic' protozoan parasite Blastocystis hominis (Zierdt, 1986). Similarly, hydrogenosomes are also believed to be a functionally heterogeneous group of organelles. The free-living microaerophilic amoebamastigote Psalteriomonas lanterna possesses two populations of hydrogenosomes. Both types react with fluoresceinisothiocyanate-labelled hydrogenase antiserum, but only the 'mature' hydrogenosomes show hydrogenase activity (by reaction with BSPT [2-(2'-benzothiazolyl)-5styryl-3-(4'-phthalhydrazidyl)tetrazolium chloride]; Coombs \& Hackstein, 1995).

A mitochondrial origin of hydrogenosomes has been suggested by a recent molecular study of $T$. vaginalis cpn-60 chaperonin coding region (Horner et al., 1996), which revealed a high sequence similarity to mitochondrial cpn-60 sequences. In addition, a cpn-60-like protein in Tritrichomonas mobilensis and Tritrichomonas augusta has been shown by Bozner (1996) to be localized in the hydrogenosome. A similar study by Bui et al. (1996) on the chaperonin proteins of T. vaginalis (cpn-10, cpn-60 and cpn-70) also demonstrated a homology with mitochondrial chaperonin proteins. However, Bui et al. (1996) reached a different conclusion to this observation. They propose that in T. vaginalis, hydrogenosomes and mitochondria are derived from the same progenitor organelle and that exploitation of aerobic niches gave rise to mitochondria whereas exploitation of anaerobic niches gave rise to hydrogenosomes. In addition, hydrogenosomes from the rumen fungus Neocallimastix frontalis $\mathrm{L} 2$, which have been described to be morphologically different to protozoan hydrogenosomes by possessing only a single membrane, have been shown to possess mitochondrial-like targeting signals on the hydrogenosomal malic enzyme (van der Giezen et al., 1997) and $\beta$-succinyl-CoA synthetase (Brondijk et al., 1996).

Morphologically, the hydrogenosomes of $M$. contortus and of other free-living anaerobic ciliates have been shown to resemble mitochondria (Finlay \& Fenchel, 1989). Embley et al. (1995) have suggested a multiple origin of hydrogenosomes in anaerobic ciliates within the radiation of aerobic ciliates and propose that a modification of pre-existing mitochondria better explains this distribution than the occurrence of multiple convergent endosymbiosis. It would appear that our results, which suggest a resemblance in the physiological role of hydrogenosomes and mitochondria, favour the idea that hydrogenosomes are modified mitochondria which have altered some of their biochemical features in order to cope more favourably with an anaerobic lifestyle. However, the broad phylogenetic distribution of hydrogenosomes and morphological differences (such as the presence of a single membrane in the hydrogenosomes of Neocallimastix) suggests that a polyphyletic origin of hydrogenosomes (Cavalier-Smith, 1987) cannot be dismissed.

The endosymbiotic methanogenic bacteria of $M$. contortus have previously been shown to increase the growth rate and yield of their host (Fenchel \& Finlay, 1991). The flow cytometric data support the theory (Fenchel $\&$ Finlay, 1992; Finlay \& Fenchel, 1992) that the endosymbionts closely associated with the hydrogenosomes act as 'hydrogen sinks', by reducing the $p \mathrm{H}_{2}$ of the cell cytoplasm. In our study, the presence of an elevated $p \mathrm{H}_{2}$ in the culture medium (and presumably in the cell cytoplasm) reduced the $\Delta \psi$ of the hydrogenosomes (Fig. 4). As a result, this may slow down the accumulation of substrates or the expulsion of products, which in turn could reduce the overall growth rate of the cell.

Further work will be concerned with isolating the hydrogenosomes, in order to further elucidate the bioenergetics of the hydrogenosome. If indeed hydrogenosomes of $M$. contortus are biochemically modified mitochondria, the elucidation of the mechanics for such a transition in function will pose challenging work. At present this work is hampered by the lack of an axenic medium for the culture of these free-living anaerobic ciliates.

\section{ACKNOWLEDGEMENTS}

We would like to thank M. Turner and K. J. Clarke for help with TEM sample preparation, R. M. Hindle for assistance 
with ciliate cultures and J. Morgan for helpful discussions. This work was carried out during a NERC postgraduate studentship (G.A.B.).

\section{REFERENCES}

Benchimol, M., Elias, C. A. \& De Souza, W. (1982). Tritrichomonas foetus: ultrastructural localisation of calcium in the plasma membrane and in the hydrogenosome. Exp Parasitol 54, 277-284.

Bozner, P. (1996). The heat shock response and major heat shock proteins of Tritrichomonas mobilensis and Tritrichomonas augusta. J Parasitol 82, 103-111.

Brondijk, T. H. C., Durand, R., van der Giezen, M., Gottschal, J. C., Prins, R. A. \& Fèvre, M. (1996). $s c s B$, a cDNA encoding the hydrogenosomal protein $\beta$-succinyl-CoA synthetase from the anaerobic fungus Neocallimastix frontalis. Mol Gen Genet 253, 315-323.

Bui, E. T. N., Bradley, P. J. \& Johnson, P. J. (1996). A common evolutionary origin for mitochondria and hydrogenosomes. Proc Natl Acad Sci USA 93, 9651-9656.

Carafoli, E. (1987). Intracellular calcium homeostasis. Annu Rev Biochem 56, 395-433.

Cavalier-Smith, T. (1987). The simultaneous origin of mitochondria, chloroplasts and microbodies. Ann N Y Acad Sci 503, 55-72.

Chapman, A., Hann, A. C., Linstead, D. \& Lloyd, D. (1985). Energydispersive X-ray microanalysis of membrane-associated inclusions in the hydrogenosomes isolated from Trichomonas vaginalis. J Gen Microbiol 115, 301-307.

Coombs, G. H. \& Hackstein, J. H. P. (1995). Anaerobic protists and anaerobic ecosystems. In Protistological Actualities, Proceedings of the Second European Congress of Protistology, pp. 90-101. Edited by G. Brugerolle \& J. P. Mignot. Clermont-Ferrand: Blaise Pascalde University.

Embley, T. M., Finlay, B. J. \& Brown, S. (1992). RNA sequence analysis shows that the symbionts in the ciliate Metopus contortus are polymorphs of a single methanogen species. FEMS Microbiol Lett 97, 57-62.

Embley, T. M., Finlay, B. J., Dyal, P. L., Hirt, R. P., Wilkinson, M. \& Williams, A. G. (1995). Multiple origins of anaerobic ciliates with hydrogenosomes within the radiation of aerobic ciliates. Proc $R$ Soc Lond B 262, 87-93.

Fenchel, T. \& Finlay, B. J. (1990). Anaerobic free living protozoa: growth efficiencies and the structure of anaerobic communities. FEMS Microbiol Ecol 74, 269-276.

Fenchel, T. \& Finlay, B. J. (1991). Endosymbiotic methanogenic bacteria in anaerobic ciliates: significance for the growth efficiency of the host. J Protozool 38, 18-22.

Fenchel, T. \& Finlay, B. J. (1992). Production of methane and hydrogen by anaerobic ciliates containing symbiotic methanogens. Arch Microbiol 157, 475-480.

Fenchel, T. \& Finlay, B. J. (1994). The evolution of life without oxygen. Am Sci 82, 22-29.

Finlay, B. J. \& Fenchel, T. (1989). Hydrogenosomes in some anaerobic protozoa resemble mitochondria. FEMS Microbiol Lett 65, 311-314.

Finlay, B. J. \& Fenchel, T. (1991). Polymorphic bacterial symbionts in the anaerobic ciliated protozoon Metopus contortus. FEMS Microbiol Lett 79, 187-190.

Finlay, B. J. \& Fenchel, T. (1992). Methanogens and other bacteria as symbionts of free-living anaerobic ciliates. Symbiosis 14, 375-390.

van der Giezen, M., Rechinger, K. B., Svendsen, I., Durand, R., Hirt, R. P., Fevre, M., Embley, T. M. \& Prins, R. A. (1997). A mitochondrial-like targeting signal on the hydrogenosomal malic enzyme from the anaerobic fungus Neocallimastix frontalis: support for the hypothesis that the hydrogenosomes are modified mitochondria. Mol Microbiol 23, 11-21.

Horner, D. S., Hirt, R. P., Kilvington, S., Lloyd, D. \& Embley, T. M. (1996). Molecular data suggest an earlier aquisition of the mitochondrion endosymbiont. Proc R Soc Lond B 263, 1053-1059.

Humphreys, M. J., Ralphs, J., Durrant, L. \& Lloyd, D. (1994). Hydrogenosomes in trichomonads are calcium stores and have a transmembrane electrochemical potential. Biochem Soc Trans 22, 324 S.

Johnson, G. D., Davidson, R. S., McNamee, K. C., Russel, G., Goodwin, D. \& Halbarrow, E. J. (1982). Fading of immunofluorescence during microscopy and study of the phenomenon and its remedy. J Immunol Methods 55, 231-242.

Lloyd, D., Lindmark, D. G. \& Muller, M. (1979). Adenosine triphosphatase activity of Tritrichomonas foetus. J Gen Microbiol 115, 301-307.

Marvin-Sikkema, F. D., Driessen, A. J. M., Gottschal, J. C. \& Prins, R. A. (1994). Metabolic energy generation in hydrogenosomes of the anaerobic fungus Neocallimastix: evidence for a functional relationship with mitochondria. Mycol Res 98, 205-212.

Muller, M. (1980). The hydrogenosome. In The Eukaryotic Microbial Cell, 30th Symposium of the Society for General Microbiology (University of Cambridge), pp. 127-142. Edited by G. W. Gooday, D. Lloyd \& A. P. J. Trinci. Cambridge: Cambridge University Press.

Smith, M. R. (1983). Reversal of 2-bromoethanesulfonate inhibition of methanogenesis in Methanosarcina sp. J Bacteriol 156, 516-523.

Turner, A. C. \& Luschbaugh, W. B. (1991). Three aspecific ATPases in Trichomonas vaginalis. Comp Biochem Physiol 100B, 691-696.

Whatley, F. R. (1981). The establishment of mitochondria: Paracoccus and Rhodopseudomonas. Ann N Y Acad Sci 361, 330-340.

Wilhelm, E. R., Battino, R. \& Wilcock, R. J. (1977). Low pressure solubility of gases in liquid water. Chem Rev 77, 219-262.

Yarlett, N., Rowlands, C., Evans, J., Yarlett, N. C. \& Lloyd, D. (1987). Nitromidazole and oxygen derived radicals detected by electron spin resonance in hydrogenosomal and cytosolic fractions from Trichomonas vaginalis. Mol Biochem Parasitol 24, 255-261.

Zierdt, C. H. (1986). Cytochrome-free mitochondria of an anaerobic protozoan Blastocystis hominis. J Protozool 33, 67-69.

Received 16 August 1996; revised 20 December 1996; accepted 13 January 1997. 